\title{
Palladium(II)-Catalyzed Directed anti-Hydrochlorination of Unactivated Alkynes with $\mathrm{HCl}$
}

\author{
Joseph Derosa, Annabelle L. Cantu, Mark N. Boulous, Miriam L. O’Duill, Joshua L. Turnbull, Zhen Liu, Daizy \\ M. De La Torre and Keary M. Engle*
}

Department of Chemistry, The Scripps Research Institute, 10550 North Torrey Pines Road, La Jolla, California 92037, United States

Supporting Information Placeholder

\begin{abstract}
A regioselective anti-hydrochlorination of unactivated alkynes is reported. The reaction utilizes in situ generated $\mathrm{HCl}$ as the source of both the $\mathrm{Cl}^{-}$and $\mathrm{H}^{+}$and is catalyzed by palladium(II) acetate, with loadings as low as 25 ppm. Removable picolinamide and 8 aminoquinoline bidentate directing groups are used to control the regioselectivity of the chloropalladation step and stabilize the resulting alkenylpalladium(II) intermediate for subsequent protodepalladation. This method provides access to a broad array of substituted alkenyl chlorides in excellent yields and with high regioselectivity. The products from this transformation were successfully derivatized via Stillecoupling to a variety of trisubstituted alkene products. Reaction progress kinetic analysis (RPKA) was performed, shedding light on a possible mechanism for this catalytic process.
\end{abstract}

\section{Introduction}

With the advent of metal-catalyzed cross-coupling chemistry, alkenyl halides have emerged as versatile building blocks for the synthesis of structurally complex target molecules. ${ }^{1}$ Though alkenyl bromides and iodides have historically been more commonly used, recent developments in ligand design have rendered alkenyl chlorides equally potent coupling partners. ${ }^{2}$ In addition to their utility as functional handles for carbon-carbon and carbon-heteroatom bond formation, alkenyl chloride moieties are also found in natural products and other bioactive compounds (Scheme 1a). ${ }^{3}$

While alkenyl chlorides are academically and industrially useful, current methods for their synthesis remain limited. With existing routes originating from carbonyl or alkyne precursors, highly substituted stereochemically pure internal alkenyl chlorides remain challenging to prepare. Additionally, these classical methods typically generate large quantities of waste and/or employ hazardous reagents, making them non-ideal for large-scale applications. ${ }^{5}$ For example, Wittig chloroolefination reactions require the use of stoichiometric chloromethyltriphenylphosphonium halide salts, ${ }^{6}$ and Takai chloroolefination depends on a large excess of $\mathrm{CrCl}_{2}$ in chloroform solvents. ${ }^{7}$ In a similar vein, hydrometalation/chlorination approaches from alkynes generally utilize stoichiometric quantities of the metal hydrides ([M-H], M = B, Al, Si, or $\mathrm{Zr}$ ), have limited functional group compatibility due to the reducing nature of the reactive metal hydrides involved, and require two steps. ${ }^{8-10}$ Nevertheless, substrate-directed variants of this chemistry constitute one of the most effective ways to access highly substituted alkenyl chlorides with control of regio- and stereochemistry (Scheme 1b).

While several different transition-metal-catalyzed approaches towards alkenyl chlorides and other alkenyl halides have also been disclosed, ${ }^{11-13}$ one underdeveloped route that is ideal from the per- spective of atom economy is the direct addition of $\mathrm{HCl}$ across an alkyne in a regio- and stereocontrolled fashion. In the absence of an activating substituent on the alkyne, ${ }^{14}$ such a reaction has been difficult to achieve. For example, direct treatment of an unactivated alkyne with $\mathrm{HCl}$ typically results in low yield of the desired alkenyl chloride, and the method has limited functional group tolerance. ${ }^{15}$

Scheme 1. Examples of alkenyl chlorides in natural products and bioactive compounds, synopsis of directed hydrometalation and of this work.

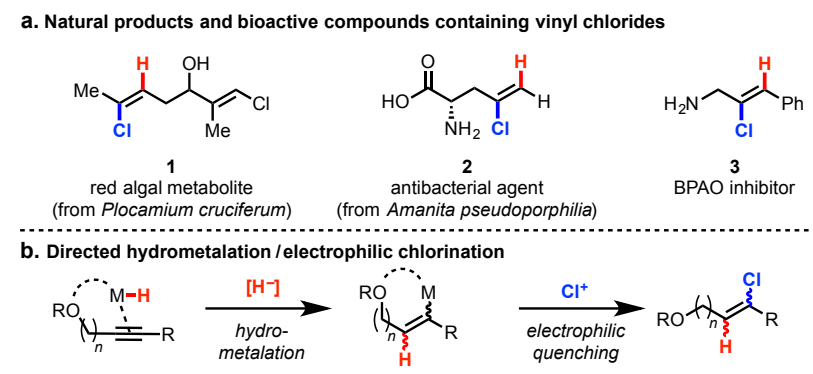

- stoichiometric metal hydride $\cdot$ strongly reducing conditions $\bullet$ inert atmosphere $\cdot \mathrm{NCS}$ as $\mathrm{Cl}^{+}$source - stereo- and regiochemistry dependent on reaction conditions, metal hydride, and tether length

c. This work: Catalytic vinyl chloride synthesis via chloropalladation/protodepalladation

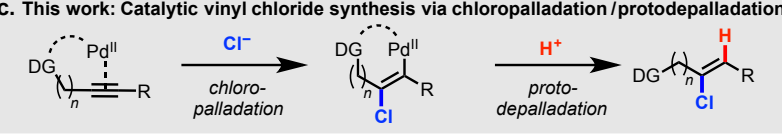

- $25 \mathrm{ppm} \mathrm{Pd"} \mathrm{catalyst} \mathrm{loading} \cdot$ broad functional group tolerance $\cdot$ compatible with air and moisture $\cdot \mathrm{HCl}$ as $\mathrm{H}^{+}$and $\mathrm{Cl}^{-}$source $\cdot$ regiochemistry controlled by palladacycle stability .

Some success has been found using transition metal catalysts to promote HX addition to alkynes. ${ }^{16}$ In particular, Sadighi, Miller, and Nolan have employed gold(I) to facilitate HF addition across alkynes. ${ }^{17}$ Notably, Miller demonstrated $>20: 1$ regioselectivity with internal dialkyl alkynes using a directing group approach. ${ }^{17 b}$ Recent- 
ly, Dérien and colleagues reported that a ruthenium(II) complex could catalyze Markovnikov syn-hydrochlorination with $\mathrm{HCl}$, though the method was limited to terminal aryl acetylenes and symmetric internal alkynes. ${ }^{18}$

Our group has recently developed a series of palladium(II)catalyzed alkene and alkyne hydrofunctionalizations that proceed by directed nucleopalladation followed by protodepalladation. ${ }^{19}$ We thus questioned whether an analogous directed halopalladation/protodepalladation sequence could be employed in a catalytic synthesis of alkenyl halides from alkynes (Scheme 1c). In conceiving this approach, we took inspiration from the aforementioned directed hydrometallation $/ \mathrm{X}^{+}$quenching approach, ${ }^{9-11}$ Miller's gold-catalyzed directed alkyne hydrofluorination, ${ }^{17 \mathrm{~b}}$ and the rich history of alkyne halopalladation reactions (vide infra). ${ }^{20-23}$

\section{Background and Historical Context}

Several literature precedents spoke to the viability of the proposed chloropalladation/protodepalladation sequence. The mechanism of alkyne chloropalladation, which can proceed with syn or anti stereochemistry depending on the reaction conditions, has been extensively studied, and several examples of well-defined chloropalladated complexes have been published. ${ }^{20}$ Moreover, alkyne chloropalladation has been employed as an elementary step in various catalytic alkyne 1,2-difunctionalization reactions. ${ }^{21}$ In 1974, Kaneda discovered that chloroallylation of alkynes could be catalyzed by $\mathrm{PdCl}_{2}(\mathrm{PhCN})_{2} .{ }^{21 a, b}$ Subsequently, Lu described several examples of tandem reactions involving chloropalladation of an propynoate derivative followed by cyclization onto a pendant alkene. ${ }^{21 c, d, f}$ In 1994, Bäckvall reported a closely related reaction that is initiated by alkyne chloropalladation, followed by cyclization onto a tethered 1,3-diene; 1,4-benzoquinone (BQ)-induced $\mathrm{C}-\mathrm{Cl}$ formation from the resultant $\pi$-allylpalladium(II) species then generates the final product. ${ }^{21 \mathrm{e}}$ Shortly thereafter, Lu disclosed a tandem reaction in which the alkenylpalladium(II) species formed via chloropalladation of an propynoic ester can participate in 1,4-conjugate addition with an $\alpha, \beta$-unsaturated carbonyl compound to achieve net 1,2-chloroalkylation of an alkyne. ${ }^{21 g}$

Examples of palladium(II)-catalyzed alkyne hydrochlorination have also been reported with terminal alkynes and haloalkynes. ${ }^{22}$ In 1997 , in a study focusing on the synthesis and characterization of anti-chloropalladated palladacycles, Dupont showed that a series of internal alkynes (namely, propargylic amines and sulfides) readily formed palladacycles when treated with $\mathrm{Pd}(\mathrm{II})$ and a $\mathrm{Cl}^{-}$source. ${ }^{23}$ In contrast, the authors reported that terminal alkynes instead underwent hydrochlorination under these conditions, and disclosed that this reaction could be rendered catalytic following reaction optimization. Specifically, in the main text, three substrates, 10-12, are described as providing $80-95 \%$ yield with catalytic $\mathrm{Pd}(\mathrm{OAc})_{2}$. In the experimental section of Ref. 23 , a yield of $69 \%$ is listed for the conversion of 10 into 13, while no yields are reported for the other two entries. Additionally, Zhu has previously demonstrated palladium(II)-catalyzed anti-hydrochlorination of haloalkynes to prepare 1,2-dihaloalkenes. ${ }^{22}$

Generally speaking, the aforementioned previous reports on catalytic transformations involving chloropalladation have involved terminal alkyne substrates, symmetrically substituted internal alkynes, or electronically activated alkynes. In the absence of steric and electronic bias, controlling the regioselectivty of this elementary step has remained a challenge.
Scheme 2. Examples of catalytic reactions involving alkyne chloropalladation

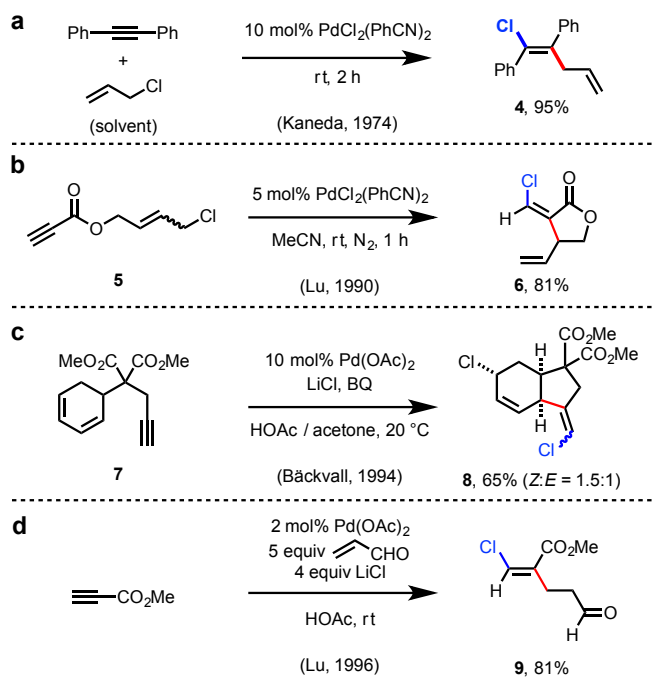

Herein, we report a regiocontrolled anti-hydrochlorination of unactivated terminal and internal alkyne substrates, including those lacking obvious steric or electronic bias. The reaction takes advantage of removable bidentate auxiliaries, which mask commonly encountered amine and carboxylic acid functional groups, to promote reactivity and control regioselectivity.

Scheme 3. Previously published examples of palladium(II)catalyzed hydrochlorination of alkynes

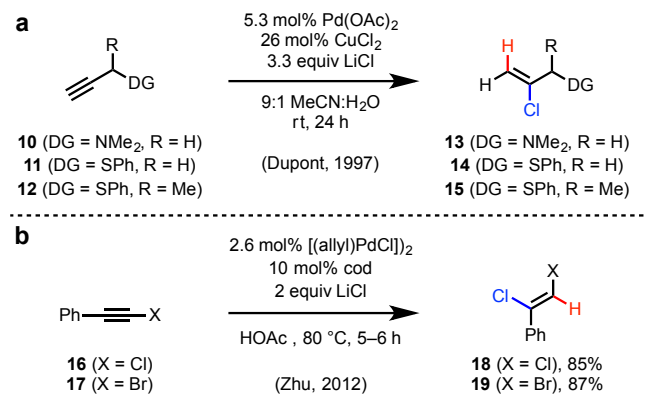

\section{Results and Discussion}

\subsection{Attempts to Reproduce Previously Published Procedure}

To initiate our study, we selected substituted propargyl amines as the pilot substrate class. In addition to the synthetic utility of the resultant chloroallylamine products, our motivation for studying these substrates stemmed from the unique bioactivity of these products. ${ }^{3}$

Our investigation commenced with revisiting the previous literature report from Dupont and coworkers, in which antihydrochlorination of terminal alkyne substrates 10-12 was described. $^{23}$ In our hands, although stoichiometric antichloropalladation of two representative internal alkynes proceeded as described (see Supporting Information), the catalytic hydrochlorination did not yield detectable quantities of the desired product 13. Instead, only Glaser homodimerization product was observed 20. (Table 1, entry 1 ) 
Table 1. Attempts to reproduce reported hydrochlorination of $\mathrm{N}, \mathrm{N}$-dimethylpropargyl amine (10), as described in Ref. $23 .^{a}$

\begin{tabular}{|c|c|c|c|c|c|c|c|c|c|c|}
\hline \multirow[b]{2}{*}{ Entry } & \multirow[b]{2}{*}{$\mathrm{Pd}(\mathrm{OAc})_{2}$} & \multirow[b]{2}{*}{$\mathrm{CuCl}_{2}$} & $\frac{\begin{array}{c}5.3 \mathrm{~mol} \% \mathrm{Pd}(\mathrm{OAc})_{2} \\
26 \mathrm{~mol} \% \mathrm{CuCl}_{2} \\
3.3 \text { equiv LiCl }\end{array}}{\begin{array}{c}9: 1 \mathrm{MeCN}: \mathrm{H}_{2} \mathrm{O} \\
\mathrm{rt}, 24 \mathrm{~h}\end{array}}$ & $\mathrm{Me}_{2} \mathrm{~N} \cup$ & 20 & \multicolumn{2}{|r|}{$\underbrace{\mathrm{H}}_{\begin{array}{c}\mathrm{Cl} \\
\text { (desired) }\end{array}}$} & \multirow[b]{2}{*}{$\%$ Glaser (20) } & \multirow[b]{2}{*}{ \% Alkenyl Chloride (13) } & \multirow[b]{2}{*}{$\%$ SM (10) } \\
\hline & & & $\mathrm{LiCl}$ & 10 & Temp. $\left({ }^{\circ} \mathrm{C}\right)$ & Atmosphere & Co-solvent & & & \\
\hline 1 & Johnson Matthey, 98\% & Ward Science, 98\% & MP Biomedical, 95\% & Acros Organics, $99 \%$ & $\mathrm{rt}$ & air & $\mathrm{H}_{2} \mathrm{O}$ & 32 & n.d. & n.d. \\
\hline 2 & Johnson Matthey, 98\% & Ward Science, $98 \%$ & MP Biomedical, 95\% & Acros Organics, $99 \%$ & $\mathrm{rt}$ & $\mathrm{O}_{2}$ & $\mathrm{H}_{2} \mathrm{O}$ & 39 & n.d. & n.d. \\
\hline 3 & Johnson Matthey, 98\% & Ward Science, 98\% & MP Biomedical, 95\% & Acros Organics, $99 \%$ & $\mathrm{rt}$ & $\mathrm{N}_{2}$ & $\mathrm{H}_{2} \mathrm{O}$ & 22 & n.d. & 35 \\
\hline 4 & Johnson Matthey, 98\% & Ward Science, $98 \%$ & MP Biomedical, 95\% & Acros Organics, $99 \%$ & 30 & air & $\mathrm{H}_{2} \mathrm{O}$ & 27 & n.d. & n.d. \\
\hline 5 & Johnson Matthey, 98\% & Ward Science, $98 \%$ & MP Biomedical, 95\% & Acros Organics, $99 \%$ & 50 & air & $\mathrm{H}_{2} \mathrm{O}$ & 29 & n.d. & n.d. \\
\hline 6 & Johnson Matthey, 98\% & Sigma-Aldrich, 99\% & MP Biomedical, 95\% & Acros Organics, $99 \%$ & $\mathrm{rt}$ & air & $\mathrm{H}_{2} \mathrm{O}$ & 25 & n.d. & n.d. \\
\hline 7 & Johnson Matthey, 98\% & Alfa Aesar, 99.995\% & MP Biomedical, 95\% & Acros Organics, $99 \%$ & $\mathrm{rt}$ & air & $\mathrm{H}_{2} \mathrm{O}$ & 30 & n.d. & n.d. \\
\hline 8 & Johnson Matthey, 98\% & Acros, $98 \%$ & MP Biomedical, 95\% & Acros Organics, $99 \%$ & $\mathrm{rt}$ & air & $\mathrm{H}_{2} \mathrm{O}$ & 28 & n.d. & n.d. \\
\hline 9 & Combi-Blocks, 98\% & Ward Science, 98\% & MP Biomedical, 95\% & Acros Organics, $99 \%$ & $\mathrm{rt}$ & air & $\mathrm{H}_{2} \mathrm{O}$ & 26 & n.d. & n.d. \\
\hline 10 & Oakwood, 98\% & Ward Science, 98\% & MP Biomedical, 95\% & Acros Organics, $99 \%$ & $\mathrm{rt}$ & air & $\mathrm{H}_{2} \mathrm{O}$ & 31 & n.d. & n.d. \\
\hline 11 & Ark Pharm, 98\% & Ward Science, 98\% & MP Biomedical, 95\% & Acros Organics, $99 \%$ & $\mathrm{rt}$ & air & $\mathrm{H}_{2} \mathrm{O}$ & 28 & n.d. & n.d. \\
\hline 12 & Sigma-Aldrich, 99.98\% & Ward Science, 98\% & MP Biomedical, 95\% & Acros Organics, $99 \%$ & $\mathrm{rt}$ & air & $\mathrm{H}_{2} \mathrm{O}$ & 36 & n.d. & $<5$ \\
\hline 13 & Johnson Matthey, 98\% & Ward Science, 98\% & MP Biomedical, 95\% & Alfa Aesar, $98 \%$ & $\mathrm{rt}$ & air & $\mathrm{H}_{2} \mathrm{O}$ & 28 & n.d. & n.d. \\
\hline 14 & Johnson Matthey, 98\% & Ward Science, 98\% & MP Biomedical, 95\% & Sigma-Aldrich, 99\% & $\mathrm{rt}$ & air & $\mathrm{H}_{2} \mathrm{O}$ & 28 & n.d. & n.d. \\
\hline 15 & Johnson Matthey, 98\% & Ward Science, 98\% & MP Biomedical, 95\% & Acros Organics, $99 \%$ & $\mathrm{rt}$ & air & $\mathrm{H}_{2} \mathrm{O}$ & 23 & n.d. & n.d. \\
\hline 16 & Johnson Matthey, 98\% & Ward Science, $98 \%$ & Acros Organics, $99 \%$ & Acros Organics, $99 \%$ & $\mathrm{rt}$ & air & $\mathrm{H}_{2} \mathrm{O}$ & 29 & n.d. & n.d. \\
\hline 17 & Johnson Matthey, 98\% & Ward Science, 98\% & Sigma-Aldrich, >99.9\% & Acros Organics, $99 \%$ & $\mathrm{rt}$ & air & $\mathrm{H}_{2} \mathrm{O}$ & 26 & n.d. & n.d. \\
\hline 18 & Johnson Matthey, 98\% & Ward Science, 98\% & MP Biomedical, 95\% & Acros Organics, $99 \%$ & $\mathrm{rt}$ & air & $2 \mathrm{M} \mathrm{HCl}$ (aq.) & 23 & n.d. & n.d. \\
\hline
\end{tabular}

${ }^{a}$ Percentages correspond to ${ }^{1} \mathrm{H}$ NMR yields using $\mathrm{CH}_{2} \mathrm{Br}_{2}$ as an internal standard. n.d. $=$ not detected.

Details pertinent to several reaction variables were not enumerated in the publication by Dupont, including atmosphere, temperature, and metal salt supplier/purity (Table 1). Thus, we next sought to systematically exclude these variables as possible origins of the discrepancy between our results and the published results. The authors did not specify the reaction atmosphere, and our isolation of Glaser homodimerization product 20 suggested to us that $\mathrm{O}_{2}$ could be responsible for facilitating consumption of the starting material along this undesired pathway. To probe this, we compared the results when the reaction was run under air, $\mathrm{O}_{2}(1 \mathrm{~atm})$, and $\mathrm{N}_{2}$ (1 atm) (entries 1-3). While the use of $\mathrm{N}_{2}$ did suppress starting material consumption as hypothesized, this was not accompanied with formation of the desired product 13 (entry 3). Next, we probed reaction temperature. In the published procedure, the reaction was described as proceeding at room temperature, which can obviously vary from laboratory to laboratory. In our own laboratory, room temperature corresponds to an average temperature of $20-22{ }^{\circ} \mathrm{C}$. Performing the reaction at elevated temperatures of 30 and $50{ }^{\circ} \mathrm{C}$ did not significantly change the product distribution (entries 4 and 5). In the published manuscript, the authors stated that all chemicals were used as received from commercial suppliers, but the suppliers were not specified. Thus, we obtained samples of 10, $\mathrm{Pd}(\mathrm{OAc})_{2}, \mathrm{CuCl}_{2}$, and $\mathrm{LiCl}$ of varying purities and from different suppliers (entries 6-17). Notably, the purity and crystal form of $\mathrm{Pd}(\mathrm{OAc})_{2}$ is special importance given the well documented effects of different forms of $\mathrm{Pd}(\mathrm{OAc})_{2}$ on reaction outcome in catalysis. ${ }^{23}$ No difference in reaction outcome was observed as a function of changing these variables. Lastly, based on observations that we discuss later in this paper, we reasoned that substitution of $\mathrm{H}_{2} \mathrm{O}$ for an aqueous solution of $\mathrm{HCl}$ could potentially promote product formation. However, when this was attempted, no substantial change in product distribution was observed (entry 18).
Finally, authentic samples of $\mathbf{1 3}$ and $\mathbf{1 4}$ were prepared using the procedure developed in this manuscript (see Supporting Information). Some of the analytical data from our samples agreed with the previously reported data, while other data did not. Notably, 13 is volatile (estimated b.p. $=40-60^{\circ} \mathrm{C}$ ), which made it most convenient to isolate as a solution in $\mathrm{Et}_{2} \mathrm{O}$. In Ref. 23, 13 is reportedly isolated in pure form after an aqueous workup, extraction with $\mathrm{Et}_{2} \mathrm{O}$, and removal of solvents; the volatility of $\mathbf{1 3}$ is not discussed. No original spectra were provided in the previous report. Thus, no firm conclusions could be drawn from comparison of the two sets of analytical data.

Overall, though we were unable to pinpoint the origin of the discrepancies between our results and those of Dupont, we did manage to rule out several possibilities. Plausible remaining explanations include the presence of an as of yet unidentified impurity that suppressed the reaction in our case or enhanced reactivity in the case of Dupont, or differences in the purity or crystal form of the metal salts involved. These issues were not examined further in the present investigation. A detailed description of experimental procedures, original NMR spectra, and accompanying data tables can be found on the Supporting Information.

Owing to the potential synthetic utility of a generally applicable directed alkyne hydrochlorination to synthesize alkenyl chlorides and based on the difficulty in reproducing this existing method and the limited scope described in the initial publication, we reasoned that it would be valuable to develop a procedure that was robust, operated at low $(<1 \mathrm{~mol} \%)$ catalyst loading, displayed good functional group tolerance, and gave high regioselectivity with internal alkyne substrates.

\subsection{Optimization of Reaction Conditions}


Table 2. Optimization of Alkyne Hydrochlorination ${ }^{a, b}$

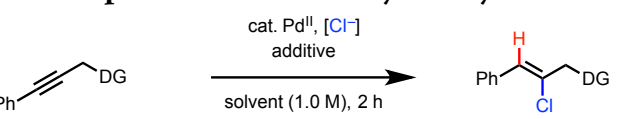

\begin{tabular}{|c|c|c|c|c|c|c|c|}
\hline Entry & DG & cat. Pd" & $\mathrm{Cl}^{-}$Source & Additive & Solvent & Temp. $\left({ }^{\circ} \mathrm{C}\right)$ & Yield $(\%$ \\
\hline 1 & A & $10 \% \mathrm{PdCl}_{2}$ & $\mathrm{LiCl}$ & -- & DMF & 80 & 10 \\
\hline 2 & A & $10 \% \mathrm{PdCl}_{2}$ & $\mathrm{LiCl}$ & $\mathrm{CuCl}_{2}$ & DMF & 80 & 33 \\
\hline 3 & A & $10 \% \mathrm{PdCl}_{2}$ & $\mathrm{LiCl}$ & $\mathrm{Cu}(\mathrm{OTf})_{2}$ & DMF & 80 & 36 \\
\hline 4 & A & -- & LiCl & $\mathrm{Cu}(\mathrm{OTf})_{2}$ & DMF & 80 & 0 \\
\hline 5 & A & $10 \% \mathrm{PdCl}_{2}$ & $\mathrm{LiCl}$ & $\mathrm{Cu}(\mathrm{OTf})_{2}$ & $\mathrm{MeCN}$ & 80 & 13 \\
\hline 6 & A & $10 \% \mathrm{PdCl}_{2}$ & $\mathrm{LiCl}$ & $\mathrm{Cu}(\mathrm{OTf})_{2}$ & toluene & 80 & 16 \\
\hline 7 & A & $10 \% \mathrm{PdCl}_{2}$ & $\mathrm{LiCl}$ & $\mathrm{Cu}(\mathrm{OTf})_{2}$ & DMA & 80 & 38 \\
\hline 8 & A & $10 \% \mathrm{PdCl}_{2}$ & - & $\mathrm{Cu}(\mathrm{OTf})_{2}$ & DMA & 80 & $<5$ \\
\hline 9 & A & $10 \% \mathrm{Pd}(\mathrm{OAc})_{2}$ & $\mathrm{SOCl}_{2}$ & $\mathrm{Cu}(\mathrm{OTf})_{2}$ & DMA & 80 & 54 \\
\hline 10 & A & $10 \% \mathrm{Pd}(\mathrm{OAc})_{2}$ & $\mathrm{AcCl} / \mathrm{H}_{2} \mathrm{O}$ & $\mathrm{Cu}(\mathrm{OTf})_{2}$ & DMA & 80 & 71 \\
\hline 11 & A & $10 \% \mathrm{Pd}(\mathrm{OAc})_{2}$ & $\mathrm{AcCl} / \mathrm{H}_{2} \mathrm{O}$ & -- & DMA & 80 & 74 \\
\hline 12 & A & $5 \% \mathrm{Pd}(\mathrm{OAc})_{2}$ & $\mathrm{BzCl} / \mathrm{H}_{2} \mathrm{O}$ & -- & DMA & 80 & 56 \\
\hline 13 & A & $5 \% \mathrm{Pd}(\mathrm{OAc})_{2}$ & $\mathrm{AcCl} / \mathrm{H}_{2} \mathrm{O}$ & -- & NMP & 80 & 69 \\
\hline 14 & A & $5 \% \mathrm{Pd}(\mathrm{OAc})_{2}$ & $\mathrm{AcCl} / \mathrm{H}_{2} \mathrm{O}$ & - & DMA & 100 & 83 \\
\hline 15 & A & $5 \% \mathrm{Pd}(\mathrm{OAc})_{2}$ & $\mathrm{AcCl} / \mathrm{H}_{2} \mathrm{O}$ & - & DMA & 120 & 96 \\
\hline 16 & B & $5 \% \mathrm{Pd}(\mathrm{OAc})_{2}$ & $\mathrm{AcCl} / \mathrm{H}_{2} \mathrm{O}$ & - & DMA & 120 & 0 \\
\hline 17 & C & $5 \% \mathrm{Pd}(\mathrm{OAc})_{2}$ & $\mathrm{AcCl} / \mathrm{H}_{2} \mathrm{O}$ & -- & DMA & 120 & 0 \\
\hline 18 & D & $5 \% \mathrm{Pd}(\mathrm{OAc})_{2}$ & $\mathrm{AcCl} / \mathrm{H}_{2} \mathrm{O}$ & - & DMA & 120 & 0 \\
\hline 19 & E & $5 \% \mathrm{Pd}(\mathrm{OAc})_{2}$ & $\mathrm{AcCl} / \mathrm{H}_{2} \mathrm{O}$ & - & DMA & 120 & 64 \\
\hline 20 & $\mathbf{F}$ & $5 \% \mathrm{Pd}(\mathrm{OAc})_{2}$ & $\mathrm{AcCl} / \mathrm{H}_{2} \mathrm{O}$ & - & DMA & 120 & 0 \\
\hline 21 & G & $5 \% \mathrm{Pd}(\mathrm{OAc})_{2}$ & $\mathrm{AcCl} / \mathrm{H}_{2} \mathrm{O}$ & - & DMA & 120 & 0 \\
\hline 22 & $\mathbf{H}$ & $5 \% \mathrm{Pd}(\mathrm{OAc})_{2}$ & $\mathrm{AcCl} / \mathrm{H}_{2} \mathrm{O}$ & - & DMA & 120 & 61 \\
\hline $23^{c}$ & A & $5 \% \mathrm{Pd}(\mathrm{OAc})_{2}$ & $\mathrm{HCl}$ in dioxane & HOAC & DMA & 120 & 81 \\
\hline 24 & A & $5 \% \mathrm{Pd}(\mathrm{OAc})_{2}$ & $\mathrm{HCl}$ in dioxane & -- & DMA & 120 & 79 \\
\hline
\end{tabular}

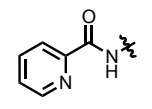

A (NHPA)

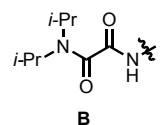

$\mathrm{DG}=$<smiles>CNC(=O)c1ncccn1</smiles>

$\mathrm{E}$

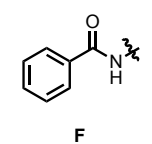

$\mathbf{F}$

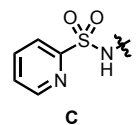

C

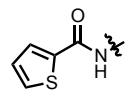

G

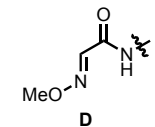

D

${ }^{a}$ Alkyne (1.0 equiv), chloride source (4.0 equiv), additive (30 mol\%). ${ }^{b}$ Yields were determined by ${ }^{1} \mathrm{H}$ NMR using $\mathrm{CH}_{2} \mathrm{Br}_{2}$ as an internal standard. ${ }^{c} \mathrm{HOAc}$ ( 6 equiv).

To develop an effective alkyne hydrochlorination with 3arylpropargylamine substrates, the reaction conditions and directing group structure were optimized in parallel (Table 2). ${ }^{25}$ Using Daugulis's $N, N$-bidentate picolinamide (PA) directing group, ${ }^{25 a}$ we first focused on reactions involving $\mathrm{LiCl}$ and $\mathrm{Cu}(\mathrm{II})$ additives (Table 1, entries 1-8). Compared with $\mathrm{LiCl}$ as the sole chloride source (entry 1), the addition of a copper(II) salt improved the yield (entries 2 and 3). Using $\mathrm{LiCl}$ and $\mathrm{Cu}(\mathrm{II})$ additives, we optimized with respect to plausible variables, including palladium source, solvent, temperature, ligand, and reaction time, without success (selected examples of which are shown in Table 1). Eventually, we turned to alternative chloride sources, and we were delighted to observe a dramatic increase in yield when the chloride nucleophile was generated in situ from hydrolysis of a suitable precursor and water (entries 9-16). Under these conditions, we discovered that copper(II) additive was no longer required (entries 10 and 11). After extensive screening, the optimal conditions were found to be with $5 \mathrm{~mol} \%$ $\mathrm{Pd}(\mathrm{OAc})_{2}$ as the catalyst and $\mathrm{AcCl} / \mathrm{H}_{2} \mathrm{O}$ as the chloride source in DMA at $120^{\circ} \mathrm{C}$ for $2 \mathrm{~h}$ (entry 15 ).

Among many mono- and bidentate directing groups tested (entries 15-22), Daugulis's N,N-bidentate picolinamide (PA) directing group delivered the highest yield. Interestingly, besides the PA group, only the pyrimidine-2-carboxamide (entry 19) and $N, N$ dimethylamino (entry 22) analogs provided detectable quantities of the desired product under optimized conditions. Other directing groups resulted in either no reaction or substrate decomposition. In all three cases where the product was observed, only a single regioisomer was detected.

It is important to note that use of anhydrous $\mathrm{HCl}$ in 1,4-dioxane as the chloride source also led to reasonably high yield of the product (entries 23 and 24), though the reaction was not as efficient as with the in situ $\mathrm{HCl}$ source, possibly due to inhibition by 1,4 dioxane.

Table 3. Hydrochlorination with Different Catalyst Loadings $^{a}$

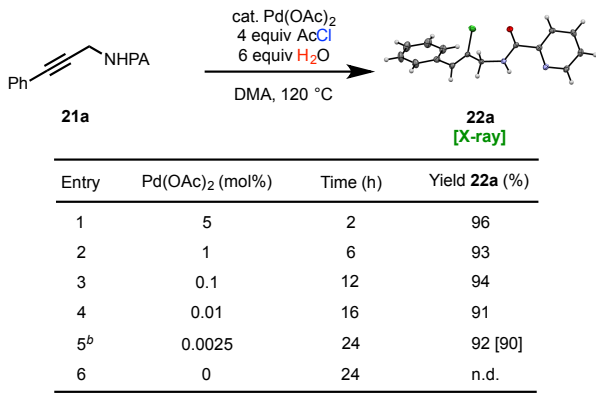

${ }^{a}$ Yields were determined by ${ }^{1} \mathrm{H}$ NMR using $\mathrm{CH}_{2} \mathrm{Br}_{2}$ as an internal standard. $n . d .=$ not detected ${ }^{b}$ The value in brackets corresponds to the yield from a trial without the magnetic stir bar.

Under our optimal reaction conditions, we ultimately found that the catalyst loading could be reduced to $25 \mathrm{ppm} \mathrm{Pd}(\mathrm{OAc})_{2}$, while still delivering $92 \%(36,800 \mathrm{TON})$ of the desired product over a longer reaction time of $24 \mathrm{~h}$ (Table 3 ). To exclude the possibility that trace metal contaminants on a previously used magnetic stir bar were contributing to the observed results, we performed the reaction without a stir bar and found a similar yield (entry 5 ). The connectivity of 22a was verified by X-ray crystallography, confirming the anticipated regio- and stereochemistry. In the absence of the $\mathrm{Pd}(\mathrm{OAc})_{2}$ catalyst, hydrochlorination product was not observed (entry 6). Moreover, no changes in catalyst performance were noted as a result of the commercial supplier of $\mathrm{Pd}(\mathrm{OAc})_{2}$.

We next considered whether any other transition metals could also promote directed alkyne hydrochlorination (Table 4). Our motivation here was threefold. First, we were curious whether other transition metals might give different stereo- or regiochemical outcomes based on their size and/or electronegativity. Second, we thought alternatively, that if a less expensive metal (e.g., Co(II)) demonstrated some level of reactivity, even if it was lower, it could be a valuable starting point for further optimization towards industrial applications. Third, the effectiveness of extremely low amounts of $\mathrm{Pd}(\mathrm{OAc})_{2}$ prompted us to consider whether trace quantities of another highly reactive metal contaminant in the commercial $\mathrm{Pd}(\mathrm{OAc})_{2}$ could be at the root of our observations. Hence, we examined several common representative metal salts under optimized conditions, and in all cases that we tested, we generally observed unreacted starting material accompanied by no more than $5 \%$ of 22a, as determined by ${ }^{1} \mathrm{H}$ NMR of the crude reaction mixture. 
Table 4. Hydrochlorination with Different Metal Catalysts ${ }^{a}$

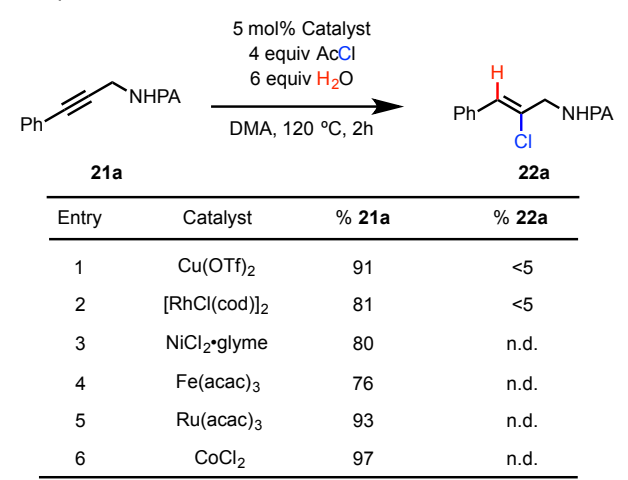

${ }^{a}$ Yields were determined by ${ }^{1} \mathrm{H}$ NMR using $\mathrm{CH}_{2} \mathrm{Br}_{2}$ as an internal standard. $n . d .=$ not detected.

Table 5. Additional control experiments in the absence of $\operatorname{Pd}(\mathrm{OAc})_{2}{ }^{a}$

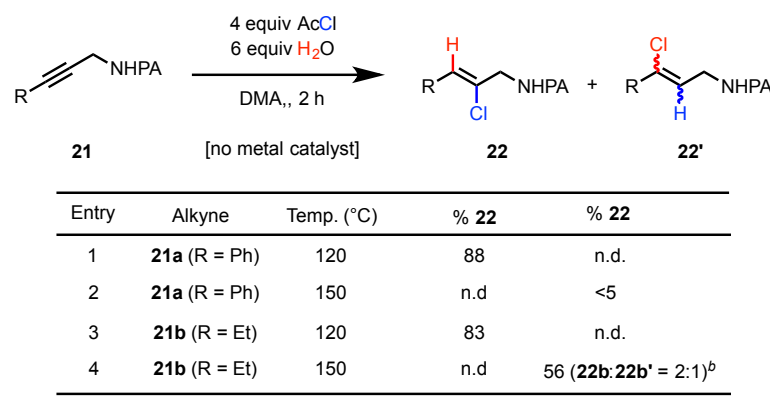

${ }^{a}$ Yields were determined by ${ }^{1} \mathrm{H}$ NMR using $\mathrm{CH}_{2} \mathrm{Br}_{2}$ as an internal standard. $n . d$. $=$ not detected. ${ }^{b}$ The stereochemistry of regioisomer 22b' was not determined.

Lastly, we performed a final set of control experiments (Table 5). As mentioned above, in the absence of $\mathrm{Pd}(\mathrm{OAc})_{2}$, the optimized reaction conditions at $120^{\circ} \mathrm{C}$ resulted in recovery of substrate $21 \mathrm{a}$. When the temperature was raised to $150^{\circ} \mathrm{C}$, significant decomposition of starting material was observed, accompanied by only trace amounts of hydrochlorination. Given the low yield $(<5 \%)$ in this experiment, we could not conclusively determine the regioselectivity of the reaction. We speculated a dialkyl alkyne substrate (21b) could potentially be more reactive with $\mathrm{HCl}$ in the absence of $\mathrm{Pd}(\mathrm{OAc})_{2}$; however, again no reaction took place at $120^{\circ} \mathrm{C}$. At an elevated temperature of $150{ }^{\circ} \mathrm{C}$, alkyne hydrochlorination was observed in the absence of $\mathrm{Pd}(\mathrm{OAc})_{2}$; however, the reaction produced a 2:1 mixture of regioisomers $\mathbf{2 2 \mathbf { b }}: \mathbf{2 2 \mathbf { b }}$ ' in $56 \%$ yield $\left({ }^{1} \mathrm{H}\right.$ NMR), compared to $87 \%$ yield of $\mathbf{2 2 \mathbf { b }}$ as a single regioisomer in the presence of catalytic $\mathrm{Pd}(\mathrm{OAc})_{2}$ (vide infra). The fact that the reaction showed modest regioselectivity in favor of product $\mathbf{2 2} \mathbf{b}$ is possibly attributable to neighboring group participation of the amide in stabilizing the putative vinyl carbocation intermediate prior to $\mathrm{Cl}^{-}$ attack. These results reaffirm that the optimized hydrochlorination reaction is indeed catalyzed by $\mathrm{Pd}(\mathrm{OAc})_{2}$ and establish that alternative non-metal-mediated $\mathrm{HCl}$ alkyne addition pathways to 21 a and $\mathbf{2 1 b}$ have higher activation energies and are far less selective.

\subsection{Evaluation of Substrate Scope}

We next investigated the substrate scope of this palladium(II)catalyzed alkyne hydrochlorination (Table 3). Reasoning that endusers sometimes desire the shortest possible reaction time, while at other times, they prioritize achieving the lowest possible catalyst loading, we tested starting materials under two sets of reaction conditions: (1) $5 \mathrm{~mol} \% \mathrm{Pd}(\mathrm{OAc})_{2}$ for $2 \mathrm{~h}$ and (2) $25 \mathrm{ppm}$ $\mathrm{Pd}(\mathrm{OAc})_{2}$ for $24 \mathrm{~h}$.

Table 6. Substrate Scope with PA Directing Group ${ }^{a}$

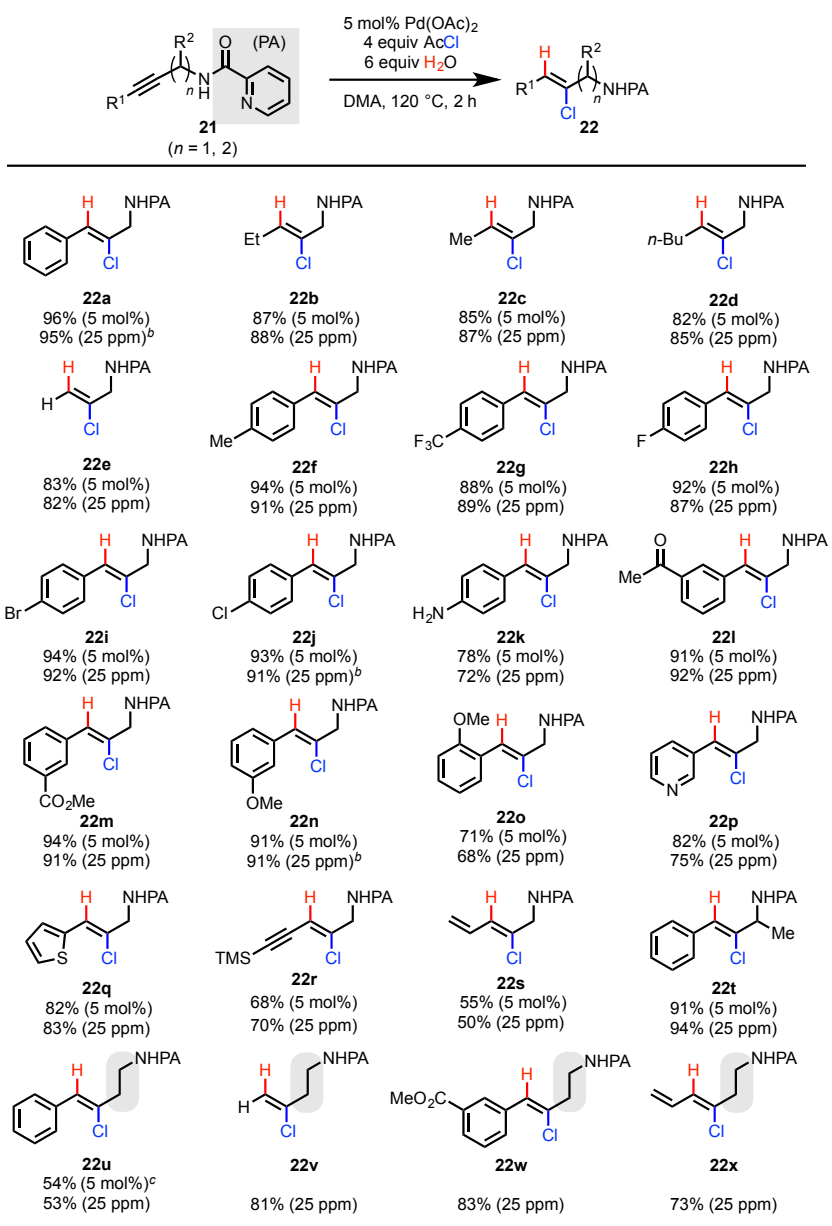

${ }^{a}$ Reaction conditions: $21 \mathbf{a}-\mathbf{x}(0.1 \mathrm{mmol}), \mathrm{AcCl}(0.4 \mathrm{mmol}), \mathrm{H}_{2} \mathrm{O}$ $(0.6 \mathrm{mmol}), \mathrm{Pd}(\mathrm{OAc})_{2}$ (5 mol\% or $\left.25 \mathrm{ppm}\right)$, DMA (1 mL), 120 ${ }^{\circ} \mathrm{C}, 2 \mathrm{~h}$ or $24 \mathrm{~h}$. Percentages represent isolated yields via column chromatography. ${ }^{b} 1.0 \mathrm{mmol}$ scale. ${ }^{c} 42 \%$ yield of hydroacetoxylation byproduct (see Ref. 26).

We first tested dialkyl alkynes (21b-d), which have no inherent steric bias between the two positions and no substituents in conjugation with the alkyne $\pi$-system. These substrates underwent the desired transformation with high efficacy and selectivity (22b-d), as did the corresponding terminal alkyne substrate (22e). Aryl rings on the alkyne with both electron-donating and -withdrawing substituents were well tolerated, providing products $22 \mathbf{f}-\mathbf{o}$ in excellent yields. Notably, carbonyl-containing functional groups (221 and $\mathbf{2 2 m}$ ), which are susceptible to reduction in classical hydrometalation/electrophilic halogenation sequences (vide supra), were preserved under these reaction conditions. Moreover, the reaction was also tolerant of a potentially coordinating free amine and a sterically encumbering ortho-substituent (22k and 220). We were also pleased to observe compatibility with two heterocycles, pyridine and thiophene (22p and 22q). Functional handles that could enable downstream diversification were preserved under the reaction conditions, such as pendant halides (22i and $\mathbf{2 2} \mathbf{j}$ ), a TMSsubstituted alkyne (22r), and a vinyl group (22s). We then ex- 
plored the effect of alkyl branching and found that while mono $\alpha$ substitution was well-tolerated (22t), gem- $\alpha, \alpha$-disubstitution led to no reaction, presumably due to added steric hindrance during approach of the chloride anion to the backside of $\mathrm{Pd}(\mathrm{II})$-bound alkyne (see Supporting Information).

In order to probe the effects of a longer tether length on reaction performance, four homopropargyl substrates were tested. We were

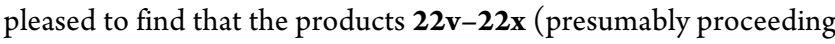
via a six-membered palladacycle) were formed in generally good yields. In the case of $\mathbf{2 2} \mathbf{u}$, a lower yield of $54 \%$ was obtained, and a hydroacetoxylation byproduct was also formed in $42 \%$ yield, which is believed to arise from competitive acetate addition. ${ }^{26}$ The presence of an electron-withdrawing group (as in the case of 22w) appeared to suppress formation of this byproduct.

Table 7. Substrate Scope with AQDirecting Group ${ }^{a}$

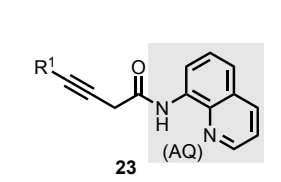

$5 \mathrm{~mol} \% \mathrm{Pd}(\mathrm{OAc})_{2}$
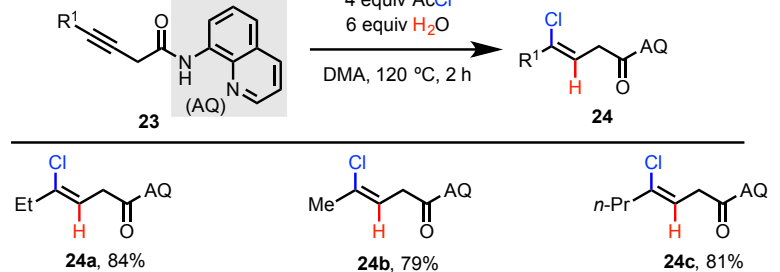

${ }^{a}$ Reaction conditions as in Table 3. Percentages represent isolated yields.

Having demonstrated the scope of this hydrochlorination protocol with propargyl and homopropargyl picolinamides, we turned our attention to alternative bidentate directing groups that could be used to mask functional groups other than amines. Based on our previous success using Daugulis's 8-aminoquinoline (AQ) auxilia$\mathrm{ry}^{25 a}$ to direct palladium(II)-catalyzed alkene hydrofunctionalization, ${ }^{19}$ we investigated a series of 3-butynoic acid derivatives bearing the AQ group. We were pleased to discover that the hydrochlorination reaction was also compatible with this substrate class, delivering the corresponding chlorovinylacetic acid products $\mathbf{2 4 a - c}$ in high yields (Table 7). Similar to examples with the PA directing group, hydrochlorination with the AQgroup was highly stereo- and regioselective. However, in contrast to the PA-directed examples with amine-derived substrates, with 3-butynoic acid bearing the AQ auxiliary, the chloride is installed distal to the directing group. Presumably the origin of this observation is again rooted in the propensity of chloropalladation to proceed to form the more thermodynamically stable 5-membered palladacycle. In this case, that would involve attack of $\mathrm{Cl}^{-}$at the $\gamma$ position of the substrate (exo to the thusly formed palladacycle).

\subsection{Synthetic Applications}

To demonstrate that the reaction was scalable, three representative products, $\mathbf{2 2} \mathbf{2}, \mathbf{2 2} \mathbf{j}$, and $\mathbf{2 2} \mathbf{n}$, were prepared on $1 \mathrm{mmol}$ scale with $25 \mathrm{ppm}$ catalyst loading, and the yields in all three cases were comparable to those in the smaller scale trials (Table 6). We then scaled up the reaction further, synthesizing 22a on gram scale, without noticeable drop in yield. With ample quantities of a representative alkenyl chloride product in hand, we then sought to identify reaction conditions to enable removal of the PA directing group in high yield. Given that alkenyl halides are known to be susceptible to HX elimination in the presence of strong base, we were concerned that this might complicate deprotection. In practice, how- ever, the PA directing group was readily cleaved via $\mathrm{KOH}$ hydrolysis in ethanol to produce free amine 23a in 92\% yield (Scheme 2).

Scheme 4. Gram-scale reaction and removal of Picolinoyl (PA) Group

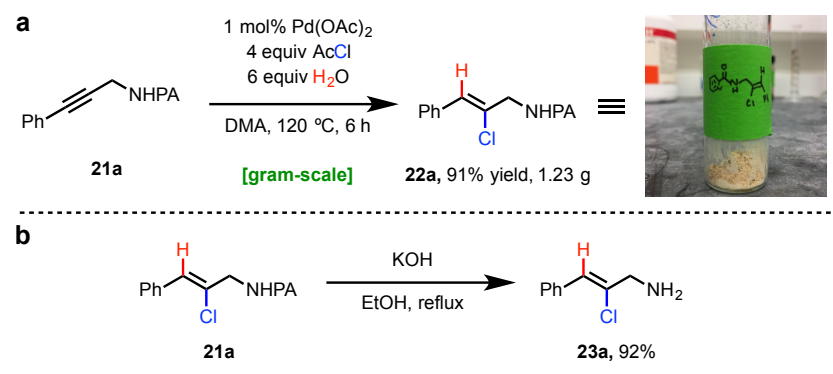

To showcase the versatility of the products, we selected one representative cross-coupling reaction, Stille coupling with organostannanes, and tested several different reaction partners under unoptimized standard conditions. To our delight, we found that heteroaryl, vinyl and alkynyl stannanes could be coupled in high yields, delivering the products of anti-hydroacylation, hydro(hetero)arylation, -hydroalkenylation, and hydroalkynylation over two high-yielding steps (26-30). The trisubstituted alkene products would be difficult to access using other methods.

Scheme 5. Product Diversification via Stille Coupling ${ }^{a}$

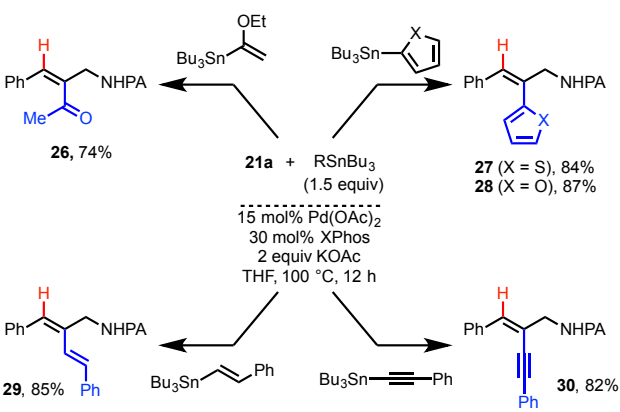

${ }^{a}$ Reaction conditions: $\mathbf{2 1 a}(0.1 \mathrm{mmol}), \mathrm{RSnBu}_{3}(0.15 \mathrm{mmol}), 15$ $\mathrm{mol} \% \mathrm{Pd}(\mathrm{OAc})_{2}, 30 \mathrm{~mol} \%$ XPhos, KOAc $(0.2 \mathrm{mmol})$, THF $(0.5$ $\mathrm{mL})$. Percentages represent isolated yields.

\subsection{Mechanistic Discussion}

We next considered the mechanism of this directed alkyne hydrochlorination reaction. This transformation could be envisioned to follow two general pathways (Scheme 6). In the first (Pathway A), the reaction would proceed as discussed in the introduction. Namely, binding of PA directing group to palladium(II) brings the alkyne moiety in close proximity to the palladium(II) center. $\pi$ Lewis acid activation would induce anti-chloropalladation. Protodepalladation of the resultant alkenylpalladium(II) species then would form the final product without a change in oxidation state at palladium. In an alternative scenario (Pathways B1 and B2), ${ }^{27}$ the reaction would begin with coordination of the palladium(II) catalyst to the $\pi$-system of the alkyne (presumably without simultaneous binding of the directing group due to geometric constraints), which would trigger $\mathrm{O}$-cyclization of the tethered amide to generate an alkyenylpalladium(II) species. ${ }^{28,29}$ This species could either undergo protodepalladation followed by chloride-mediated oxazoline ring opening (Pathway B2) ${ }^{30}$ or could be attacked by chloride, 
triggering rearrangement to intercept the chloropalladated palladacycle intermediate in Pathway A (Pathway B1).

\section{Scheme 6. Potential Pathways for Product Formation}
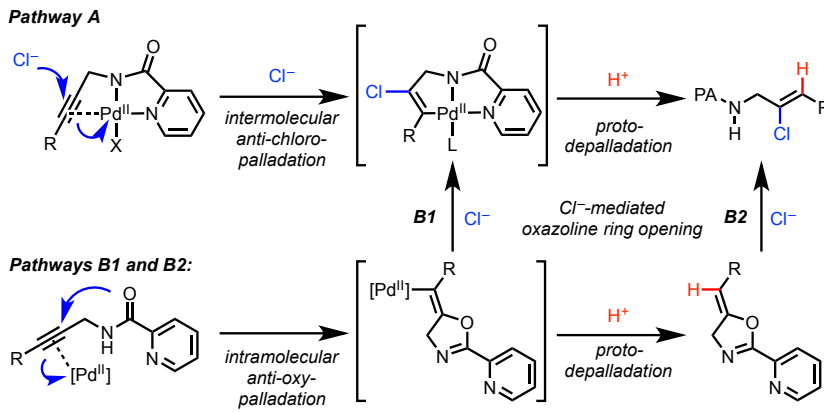

To distinguish between these possibilities, we first noted that the hydrochlorination reaction still proceeded (albeit in diminished yield) using a dimethylamino directing group (Table 2, entry 22), which lacks the requisite carbonyl moiety for Pathways B1 and B2. To probe this further, we independently prepared putative oxazoline intermediate $\mathbf{3 1}$ and resubmitted it to the reaction conditions in the presence and absence of $\mathrm{Pd}(\mathrm{OAc})_{2}$ (Table 8). These experiments led to substrate decomposition, accompanied by at most trace product formation. These results are inconsistent with Pathway B2. While we were unable to definitely rule out Pathway B1, we favor Pathway A given the aforementioned results with the dimethylamino directing group and in light of it being more consistent with the extensive body of literature on alkyne chloropalladation.

\section{Table 8. Oxazoline Control Experiments ${ }^{a}$}

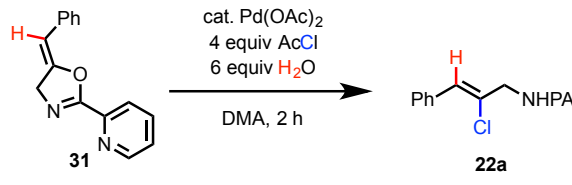

\begin{tabular}{ccccc}
\hline Entry & $\mathrm{Pd}(\mathrm{OAc})_{2}$ & Temp. $\left({ }^{\circ} \mathrm{C}\right)$ & $\% \mathbf{3 1}$ & $\%$ 22a \\
\hline 1 & -- & 120 & 34 & n.d. \\
2 & -- & 150 & $<5$ & $<5$ \\
3 & $5 \mathrm{~mol} \%$ & 120 & 41 & n.d. \\
4 & $5 \mathrm{~mol} \%$ & 150 & $<5$ & $<5$ \\
\hline
\end{tabular}

${ }^{a}$ Yields were determined by ${ }^{1} \mathrm{H}$ NMR using $\mathrm{CH}_{2} \mathrm{Br}_{2}$ as an internal standard. $n . d .=$ not detected.

\section{Scheme 7. Deuterium Incorporation Study}

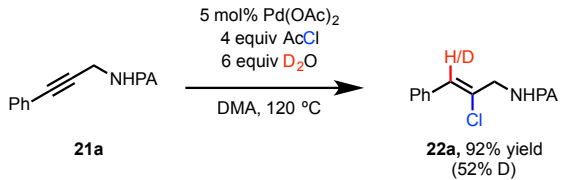

To identify the origin of the hydrogen atom under catalytic conditions, we carried out a deuterium incorporation study where $\mathrm{H}_{2} \mathrm{O}$ was substituted with $\mathrm{D}_{2} \mathrm{O}$ in dry DMA under otherwise standard reaction conditions (Scheme 7 ). The resulting product contained approximately $52 \%$ deuterium at the vinylic position, with no other position showing deuterium incorporation. The $\mathrm{N}-\mathrm{H}$ bond of the substrate presumably serves as the source of hydrogen atoms in this experiment. This result is consistent with a protodepalladation mechanism. Additionally, given that there are $\geq 4$ equiv of reactive $\mathrm{D}^{+}$relative to $\mathrm{H}^{+}$and only $52 \%$ deuterium incorporation is observed, it also suggests that there is a large kinetic isotope effect (KIE) (vide infra).
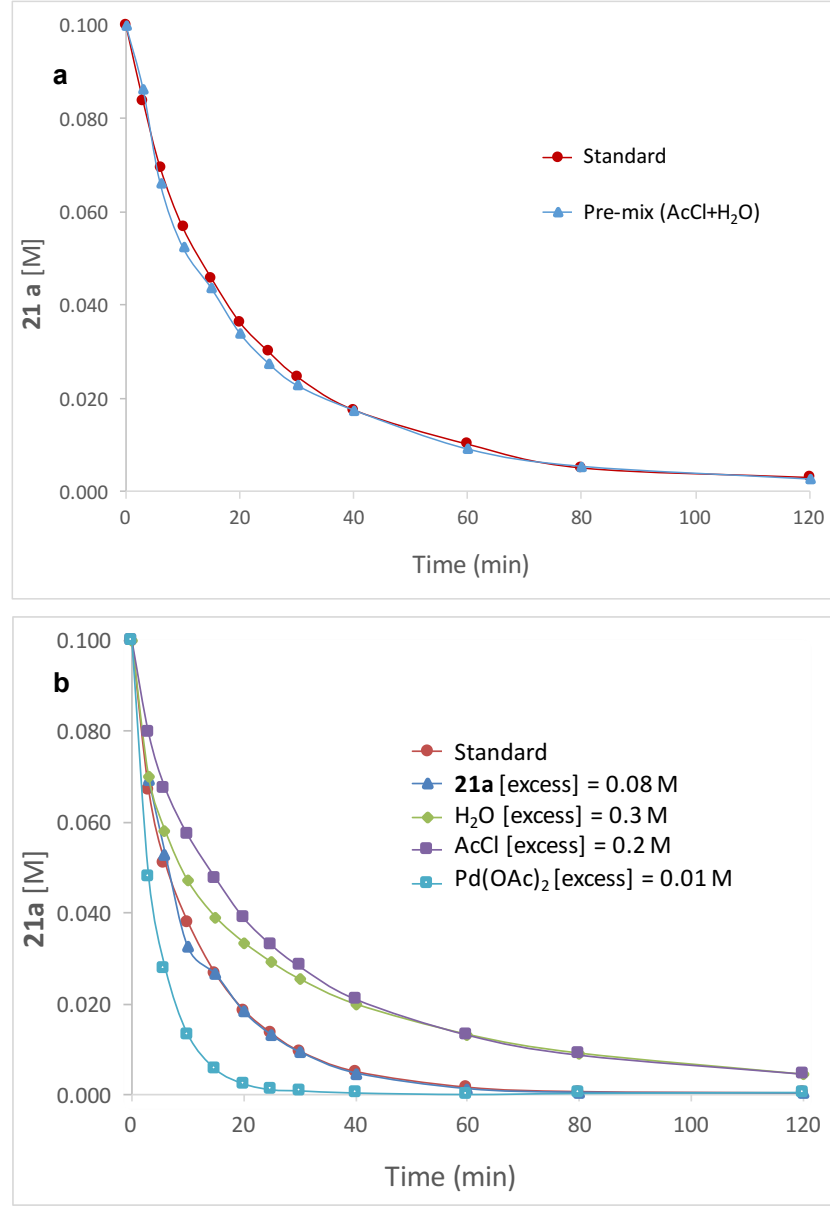

Figure 1. Probing the effect of acid chloride hydrolysis on global kinetics by carrying out different ["excess"] experiments in conjunction with a "pre-mix" addition experiment.

a) Hydrochlorination using $\mathrm{Pd}(\mathrm{OAc})_{2}(0.005 \mathrm{M}), 21 \mathrm{a}(0.1 \mathrm{M})$; red curve (standard): $\mathrm{H}_{2} \mathrm{O}(0.6 \mathrm{M})$ added prior to $\mathrm{AcCl}(0.4 \mathrm{M})$; blue curve (pre-mix): solution of $\mathrm{H}_{2} \mathrm{O}(0.6 \mathrm{M})$ and $\mathrm{AcCl}(0.4 \mathrm{M})$ stirred at $120{ }^{\circ} \mathrm{C}$ for $1 \mathrm{~h}$ and then added; b) Hydrochlorination different-excess experiments; red curve (standard): 21 a $(0.1 \mathrm{M})$, $\mathrm{Pd}(\mathrm{OAc})_{2}(0.005 \mathrm{M}), \mathrm{H}_{2} \mathrm{O}(0.6 \mathrm{M}), \mathrm{AcCl}(0.4 \mathrm{M})$; all other experiments correspond to the standard, with different-excess components as listed above.

We next performed reaction progress kinetic analysis (RPKA), which is an established tool for elucidating the mechanistic details of catalytic processes from a minimum number of experiments. ${ }^{31}$ After first establishing a robust, standard protocol for monitoring reaction kinetics by injecting $\mathrm{AcCl}$ to a preheated solution of the other reactants and $\mathrm{Pd}(\mathrm{OAc})_{2}$ in $\mathrm{DMA}$, we wanted to determine whether the rate of acetyl chloride hydrolysis was relevant the global rate of hydrochlorination. To test this, we compared the rate profile of a reaction under standard conditions to one in which the acetyl chloride and water had been premixed. Specifically, in this latter trial, a solution of acetyl chloride and water in DMA was heated to $120^{\circ} \mathrm{C}$ for one hour, at which point an aliquot was taken and injected into a solution of the other reaction components to initiate the reaction. The resulting overlay of the premixed trial and the standard trial allowed us to conclude that the hydrolysis of acid chloride to release $\mathrm{HCl}$ in solution does not influence the global rate, consistent with the notion that the $\mathrm{AcCl}$ is completely hydro- 
lyzed at the beginning of the reaction. This means that provided $\left[\mathrm{H}_{2} \mathrm{O}\right]_{0} \geq[\mathrm{AcCl}]_{0},[\mathrm{HCl}]_{0}=[\mathrm{AcCl}]_{0}($ Figure 1a $)$. In the alternative scenario where $\mathrm{H}_{2} \mathrm{O}$ is the limiting reagent in hydrolysis, more complex kinetics are anticipated, which outside of the scope of the current discussion.
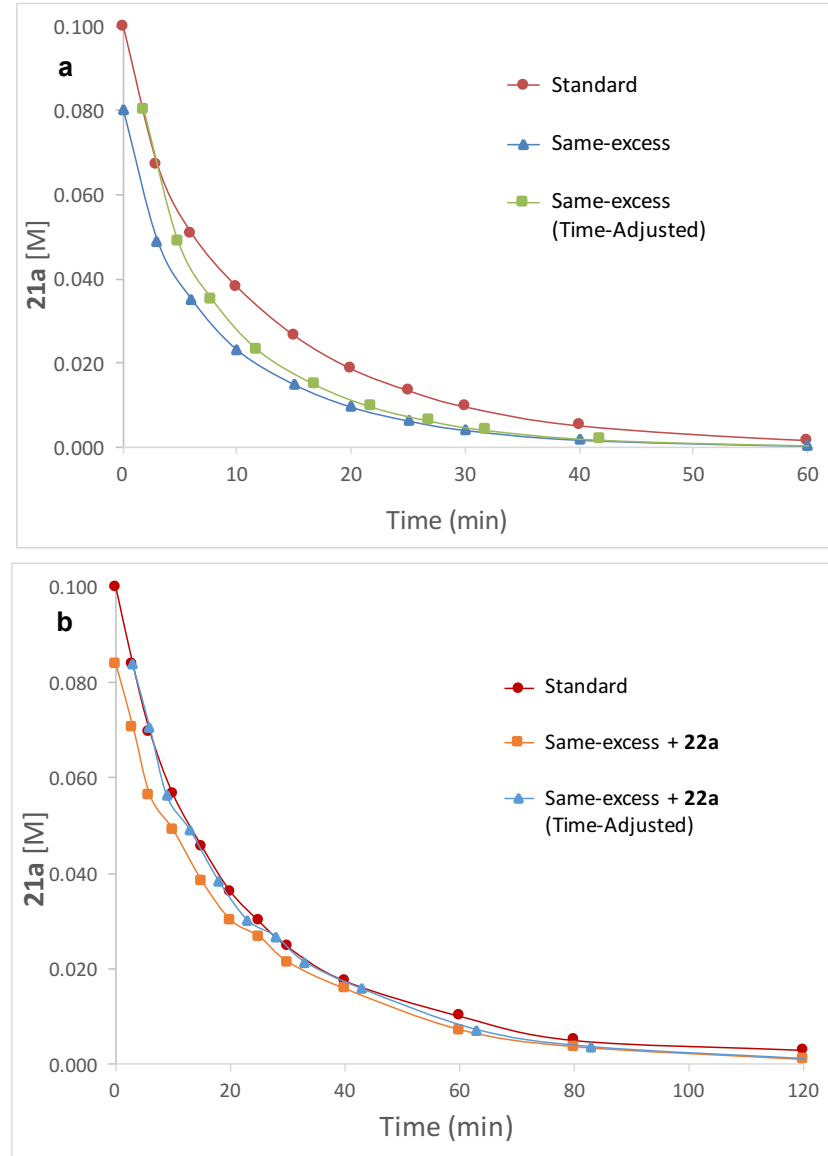

Figure 2. Same-excess experiments designed to identify the potential product inhibition or catalyst deactivation.

a) Hydrochlorination using $\mathrm{Pd}(\mathrm{OAc})_{2}(0.005 \mathrm{M})$; red curve (standard): 21a $(0.1 \mathrm{M}), \mathrm{H}_{2} \mathrm{O}(0.6 \mathrm{M}), \mathrm{AcCl}(0.4 \mathrm{M})$; blue curve (same-excess): $\left.21 \mathrm{a}(0.08 \mathrm{M}), \mathrm{H}_{2} \mathrm{O}(0.58 \mathrm{M}), \mathrm{AcCl}(0.38 \mathrm{M}) ; \mathrm{b}\right)$ Hydrochlorination using $\mathrm{Pd}(\mathrm{OAc})_{2}(0.005 \mathrm{M})$; red curve (standard), same as above; orange curve (same-excess + 22a): 21a $(0.08$ M), 22a (0.02 M), $\mathrm{H}_{2} \mathrm{O}(0.58 \mathrm{M}), \mathrm{AcCl}(0.38 \mathrm{M})$.

We next sought to understand the orders of the various reaction components. To do this, we performed a series of different excess experiments (Figure $1 \mathrm{~b}$ ). A change in concentration of alkyne substrate (21a) did not change the rate, indicating zero order kinetics in substrate. A lesser concentration of $\mathrm{AcCl}$ led to a lower rate, indicating positive-order kinetics in $[\mathrm{AcCl}]$. Finally, an increase in the concentration of $\mathrm{Pd}(\mathrm{OAc})_{2}$ led to a higher rate, indicating the reaction is positive-order in catalyst. In summary, experiments revealed that the reaction is zero-order in alkyne substrate (21a), positive-order in $\mathrm{Pd}(\mathrm{OAc})_{2}$, and positive-order in $\mathrm{HCl}$. More precise rate orders of acetyl chloride and water could not be determined under the experimental conditions. In addition to these different-excess experiments, we ran a same-excess experiment. The lack of overlay between the two rate profiles indicated that there was potential for product inhibition or catalyst deactivation (Figure 2a). Subsequently, a same excess experiment with added product led to overlay with the standard curve, consistent with product inhibition (Figure 2b).

To follow up on the deuterium incorporation experiment discussed above, we measured the reaction rate when $\mathrm{H}_{2} \mathrm{O}$ was replaced with $\mathrm{D}_{2} \mathrm{O}$. The experiments revealed a KIE of 1.8 . We note that this experimental KIE value likely understates the true KIE, given that the $\mathrm{N}-\mathrm{H}$ bond of the substrate introduces exchangeable $\mathrm{H}^{+}$equivalents into the system. Taken together, these mechanistic experiments are consistent with protodepalladation as the ratelimiting step in the catalytic cycle.

\section{Scheme 8. Proposed Catalytic Cycle}

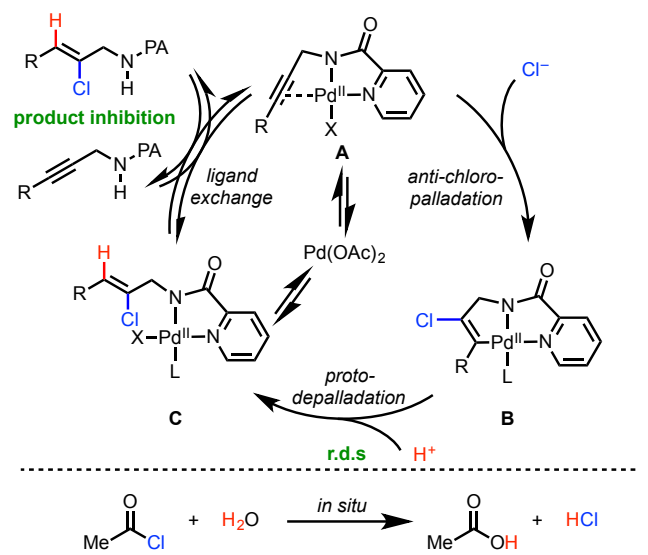

A potential catalytic cycle for the hydrochlorination reaction is depicted in Scheme 4. Initially, palladium(II) acetate coordinates to the picolinamide directing group, exchanging an acetate for the deprotonated amide via ligand transfer to form chelated intermediate A. Upon hydrolysis of acetyl chloride, chloride addition to the alkyne favors the formation of the more stable 5-membered palladacycle, intermediate B. Upon treatment with acid at elevated temperatures, a protodepalladation event affords hydrochlorinated intermediate $\mathbf{C}$, which can exchange off the product for a new substrate molecule to close the catalytic cycle.

\section{Conclusion}

In summary, we have established a new method for regioselective hydrochlorination of terminal and internal alkynes with broad substrate scope and high functional group tolerance using $25 \mathrm{ppm}$ $\mathrm{Pd}(\mathrm{OAc})_{2}$ as the catalyst. The removable bidentate PA and AQ auxiliaries direct the regiochemical course of the reaction and stabilize the resulting palladacycle intermediates. After the reaction they can be cleaved to reveal synthetically useful functional groups. The hydrochlorinated products can conveniently be converted to a variety of synthetically versatile trisubstituted alkenes via crosscoupling. A plausible catalytic cycle involving directed antichloropalladation followed by rate-limiting protodepalladation was supported by RPKA. Broadly speaking, this work establishes directed halopalladation as a potentially versatile strategy for carbonhalogen bond formation.

\section{ASSOCIATED CONTENT}

\section{Supporting Information}


Experiment details, spectra data, copies of ${ }^{1} \mathrm{H}$ and ${ }^{13} \mathrm{C}$ NMR spectra, and X-ray crystallographic data. These materials are available free of charge via the Internet at http://pubs.acs.org.

\section{AUTHOR INFORMATION}

\section{Corresponding Author}

*E-mail: keary@scripps.edu

\section{Notes}

The authors declare no competing financial interest.

\section{ACKNOWLEDGMENT}

This work was financially supported by TSRI and Pfizer, Inc. We gratefully acknowledge the NIH for a RISE fellowship (Award Number R25GM071638, A. L. C.), the DAAD for a postdoctoral fellowship (M. L. O.), the Chemistry Department at King's College, London for an Alumni Overseas Summer Studentship (J. L. T.), and the Life Sciences Summer Internship program (D. M. D.). We thank Dr. Dee-Hua Huang for assistance with NMR spectroscopy. We are grateful to Prof. Donna G. Blackmond (TSRI) for assistance with design and interpretation of RPKA experiments. We further thank Prof. Phil S. Baran (TSRI), Prof. Jin-Quan Yu (TSRI), Prof. Ryan A. Shenvi (TSRI), Prof. Will R. Gutekunst (Georgia Tech), Dr. Kin S. Yang (Gilead), and Dr. Zachary Wickens (Harvard). Jacob T. Edwards (Baran Lab, TSRI) and Tyler G. Saint-Denis (Yu lab, TSRI) are acknowledged for support and encouragement.

\section{REFERENCES}

(1) (a) Nicolaou, K. C.; Bulger, P. G.; Sarlah, D. Angew. Chem., Int. Ed. 2005, 44, 4442-4489. (b) Evano, G.; Blanchard, N.; Toumi, M. Chem. Rev. 2008, 108, 3054-3131. (c) Jana, R.; Pathak, T. P.; Sigman, M. S. Chem. Rev. 2011, 111, 1417-1492.

(2) For selected examples of cross-coupling with vinyl chlorides, see: (a) Littke, A. F.; Dai, C.; Fu, G. C. J. Am. Chem. Soc. 2000, 122, 4020-4028. (b) Dai, C.; Fu, G. C. J. Am. Chem. Soc. 2001, 123, 2719-2724. (c) Su, W.; Urgaonkar, S.; McLaughlin, P. A.; Verkade, J. G. J. Am. Chem. Soc. 2004, 126, 16433-16439.

(3) Examples of vinylchlorides in natural products and bioactive compounds: (a) Blunt, J. W.; Hartshorn, M. P.; Munro, M. H. G.; Yorke, S. C. Tetrahedron Lett. 1978, 19, 4417-4418. (b) Esaki, N.; Takada, H.; Moriguchi, M.; Hatanaka, S.; Tanaka, H.; Soda, H., K. Biochemistry 1989, 28, 2111-2116. (c) Kim, J.; Zhang, Y.; Ran, C.; Sayre, L. M. Bioorg. Med. Chem. 2006, 14, 1444-1453.

(4) Newhouse, T.; Baran, P. S.; Hoffman, R. W. Chem. Soc. Rev. 2009, 38, 3010-3021.

(5) (a) Sotaro, M.; Yu, I.; Katsuo, F.; Yutaka, O.; Harukichi, H. Bull. Chem. Soc. Jpn. 1979, 52, 1197-1202. For related examples to access other alkenyl halides, see: (b) Stork, G.; Zhao, K. Tetrahedron Lett. 1989, 30, 2173-2174. (c) Olpp, T.; Bruckner, R. Synthesis 2004, 2135-2152. (d) Hodgson, D. M.; Arif, T. J. Am. Chem. Soc. 2008, 130, 16500-16501.

(6) (a) Takai, K.; Nitta, K.; Utimoto, K. J. Am. Chem. Soc. 1986 108, 7408-7410. (b) Takai, K.; Ichiguchi, T.; Hikasa, S. Synlett 1999, 1268-1270.

(7) For selected examples of stoichiometric hydrometalation/halogenation sequences with alkynes, see: (a) Brown. $\mathrm{H}$.
C.; Hamaoka, T.; Ravindran, N.; Subrahmanyam, C.; Somayaji, V.; Bhat, N. G. J. Org. Chem. 1989, 54, 6075-6079. (b) Masuda, Y.; Hoshi, M.; Arase, A. J. Chem. Soc. Perkin Trans. 1 1992, 2725-2726. (c) Barluenga, J.; Alvarez-García, L. J.; González, J. M. Tetrahedron Lett. 1995, 36, 2153-2156. (d) Gao, F.; Hoveyda, A. H. J. Am. Chem. Soc. 2010, 132, 10961-10963.

(8) Hoveyda, A. H.; Evans, D. A.; Fu, G. C. Chem. Rev. 1993, 93, 1307-1370.

(9) In a pioneering early study on directed anti-hydroalumination followed by quenching with $\mathrm{I}_{2}$, it was shown that the regiochemistry of the hydroalumination step could be modulated by careful tuning of the reaction conditions: Corey, E. J.; Katzenellenbogen, J. A.; Posner, G. H. J. Am. Chem. Soc. 1967, 89, 4245-4247.

(10) For examples of directed hydrometalation followed by quenching with NCS to access alkenyl chlorides, see: (a) Gu, Y.; Snider, B. B. Org. Lett. 2003, 5, 4385-4388. (b) Martín, M. J.; Coello, L.; Fernández, R.; Reyes, F.; Rodríguez, A.; Murcia, C.; Garranzo, M.; Mateo, C.; Sánchez-Sancho, F.; Bueno, S.; de Eguilior, C.; Francesch, A.; Munt, S.; Cuevas, C. J. Am. Chem. Soc. 2013 , 135, 10164-10171. (c) Xu, S.; Unabara, D.; Uemura, D.; Arimoto, H. Chem. Asian J. 2014, 9, 367-375. (d) Ray, A.; Mukherjee, S.; Das, J.; Bhandari, M. K.; Du, H.; Yousufuddin, M.; Lovely, C. J. Tetrahedron Lett. 2015, 56, 3518-3522.

(11) For a review on catalytic approaches to $\mathrm{C}-\mathrm{X}$ bond formation, see: Petrone, D. A.; Ye, J.; Lautens, M. Chem. Rev. 2016, 116, 8003-8104.

(12) Olefin metathesis approaches to alkenyl halides: (a) Macnaughtan, M. L.; Johnson, M. J. A.; Kampf, J. W. J. Am. Chem. Soc. 2007, 129, 7708-7709. (b) Koh, M. J.; Nguyen, T. T.; Zhang, H.; Schrock, R. R.; Hoveyda, A. H. Nature 2016, 531, 459-465.

(13) Alkenyl bromide synthesis from alkynes using catalytic [CuH] and $\mathrm{Br}^{+}$, see: Uehling, M. R.; Rucker, R. P.; Lalic, G. J. Am. Chem. Soc. 2014, 136, 8799-8803.

(14) Regioselective hydrohalogenation of electron-rich or -poor alkynes with $\mathrm{H}^{+} / \mathrm{X}^{-}$sources: (a) Ma, S.; Lu, X.; Li, Z. J. Org. Chem. 1992, 57, 709-713; (b) Yu, W.; Jin, Z. J. Am. Chem. Soc. 2000, 122, 9840-9841; (c) Su, M.; Yu, W.; Jin, Z. Tetrahedron Lett. 2001, 42, 3771-3774; (d) Duncan, D.; Livinghouse, T. J. Org. Chem. 2001, 66, 5237-5240. (e) Mulder, J. A.; Kurtz, K. C. M.; Hsung, R. P.; Coverdale, H.; Frederick, M. O.; Shen, L.; Zificsak, C. A. Org. Lett. 2003, 5, 1547-1550; Coelho, A.; Novoa, H.; Peeters, O. M.; Blaton, N.; Alvarado, M.; Sotelo, E. Tetrahedron 2005, 61, 4785-4791. (f) Feray, L.; Perfetti, P.; Bertrand, M. P. Synlett 2009, 2009, 8991. (g) Kawaguchi, S.-i.; Ogawa, A. Org. Lett. 2010, 12, 1893-1895.

(15) (a) Carothers, W. H.; Coffman, D. C. J. Am. Chem. Soc. 1932, 54, 4071-4076. (b) Fahey, R. C.; Lee, D. J. J. Am. Chem. Soc. 1966, 88, 5555-5560. (c) Cousseau, J.; Gouin, L. J. Chem. Soc. Perkin Trans. 1 1977, 1797-1801. (d) Griesbaum, K.; Rao, V. V. R.; Leifker, G. J. Org. Chem. 1982, 47, 4975-4981. (e) Kropp, P. J.; Crawford, S. D. J. Org. Chem. 1994, 59, 3102-3112.

(16) $\mathrm{HgCl}_{2}$-mediated Markovnikov $\mathrm{HCl}$ addition to propargyl alcohol: Reppe, W. Justus Liebigs Ann. Chem. 1955, 596, 38-79.

(17) For HF addition to alkynes catalyzed by gold, see: (a) Akana, J. A.; Bhattacharyya, K. X.; Müller, P.; Sadighi, J. P. J. Am. Chem. Soc. 2007, 129, 7736-7737. (b) Gorske, B. C.; Mbofana, C. T.; Miller, S. J. Org. Lett. 2009, 11, 4318-4321. (c) Nahra, F.; Patrick, S. R.; Bello, D.; Brill, M.; Obled, A.; Cordes, D. B.; Slavin, A. M. Z.; O’Hagan, D.; Nolan, S. P. Chem CatChem 2015, 7, 240- 244. 
(18) Dérien, S., Klein, H.; Bruneau, C. Angew. Chem. Int. Ed. 2015, 54, 12112-12115.

(19) (a) Gurak, J. A., Jr.; Yang, K. S.; Liu, Z.; Engle, K. M. J. Am. Chem. Soc. 2016, 138, 5805-5808. (b) Yang, K. S.; Gurak, J. A., Jr.; Liu, Z.; Engle, K. M. J. Am. Chem. Soc. 2016, 138, 14705-14712. (c) Liu, Z.; Derosa, J.; Engle, K. M. 2016, J. Am. Chem. Soc. 2016, 138, 13076-13081.

(20) (a) Bäckvall, J.-E.; Nilsson, Y. I. M.; Gatti, R. G. P. Organometallics 1995, 14, 4242-4246. (b) Zanini, M. L.; Meneghetti, M. R.; Ebeling, G.; Livotto, P. R.; Rominger, F.; Dupont, J. Inorg. Chim. Acta 2002, 350, 527-536. (c) Tsuji, J. Palladium Reagents and Catalysts, John Wiley \& Sons: Chichester, U. K., 2004.

(21) For examples of Pd-catalyzed alkyne difunctionalization via chloropalladation, see: (a) Kaneda, K.; Kawamoto, F.; Fujiwara, Y.; Imanaka, T.; Teranishi, S. Tetrahedron Lett. 1974, 15, 1067-1070. (b) Kaneda, K.; Uchiyama, T.; Fujiwara, Y.; Imanaka, T.; Teranishi, S. J. Org. Chem. 1979, 44, 55-63. (c) Ma, S.; Lu, X. J. Chem. Soc., Chem. Commun. 1990, 733-734. (d) Ma, S.; Lu, X. J. Org. Chem. 1993, 58, 1245-1250. (e) Bäckvall, J.-E.; Nilsson, Y. I. M.; Andersson, P. G.; Gatti, R. G. P.; Wu, J. Tetrahedron Lett. 1994, 35, 5713-5716 (f) Ji, J. Zhang, C.; Lu, X. J. Org. Chem. 1995, 60, 1160 1169. (g) Wang, Z.; Lu, X. Chem. Commun. 1996, 535-536. (h) Thadani, A. N.; Rawal, V. H. Org. Lett. 2002, 4, 4321-4323. (i) Zhu, G.; Zhang, Z. J. Org. Chem. 2005, 70, 3339-3341. (j) Lu, Z.; Kong, W.; Yuan, Z.; Zhao, X.; Zhu, G. J. Org. Chem. 2011, 76, 8524-8529. (k) Topolovcan, N.; Panov, I.; Kotora, M. Org. Lett. 2016, 18, 3634-3637.

(22) Zhu, G.; Chen, D.; Wang, Y.; Zheng, R. Chem. Commun. 2012, 48, 5796-5798.

(23) Dupont, J.; Basso, N. R.; Meneghetti, M. R.; Konrath, R. A.; Burrow, R.; Horner, M. Organometallics 1997, 16, 2386-2391.

(24) (a) Bajwa, S. E.; Storr, T. E.; Hatcher, L. E.; Williams, T. J.; Baumann, C. G.; Whitwood, A. C.; Allan, D. R.; Teat, S. J.; Raithby, P. R.; Fairlamb, I. J. S. Chem. Sci. 2012, 3, 1656-1661. (b) Carole, W. A.; Bradley, J.; Sarwar, M.; Colacot, T. J. Org. Lett. 2015, 17, 5472-5475. (c) Carole, W. A.; Colacot, T. J. Chem. Eur. J. 2016, 22, $7686-7695$.

(25) (a) Zaitsev, V. G.; Shabashov, D.; Daugulis, O. J. Am. Chem. Soc. 2005, 127, 13154-13155. (b) Shabashov, D.; Daugulis, O. J. Am. Chem. Soc. 2010, 132, 3965-3972. (c) Wang, C.; Chen, C.; Zhang, J.; Han, J.; Wang, Q.; Guo, K.; Liu, P.; Guan, M.; Yao, Y.; Zhao, Y. Angew. Chem. Int. Ed. 2014, 53, 9884-9888. (d) Fan, M.; Ma, D. Angew. Chem. Int. Ed. 2013, 125, 12374-12377; (e) Rodriguez, N.; Romero-Revilla, J. A.; Fernandez-Ibanez, M. A.; Carretero, J. C. Chem. Sci. 2013, 4, 175-179. For reviews on bidentate directing groups in $\mathrm{C}-\mathrm{H}$ activation, see: (f) Rouquet, G.; Chatani, N. Angew. Chem. Int. Ed. 2013, 52, 11726-11743. (g) Daugulis, O.; Roane, J.; Tran, L. D. Acc. Chem. Res. 2015, 48, 1053-1064.

(26) Under the reaction conditions described, it is believed that acetic acid generated in situ can also undergoes an analogous reaction to yield the vinyl acetate. The hydroacetoxylation product has the opposite regio- and stereochemical configuration. For selected examples of palladium(II)-catalyzed hydroacetoxylation/hydration of alkynes, see: (a) Zhang, Q.; Lu, X.; Han, X. J. Org. Chem. 2001, 66, 7676-7684. (b) Zhang, Z.; Wu, L.; Liao, J.; Wu, W.; Jiang, H.; Li, J.; Li, J. J. Org. Chem. 2015, 80, 7594-7603. (c) Vinoth, P.; Nagarajan, S.; Maheswari, C. U.; Sudalai, A.; Pace, V.; Sridharan, V. Org. Lett. 2016, 18, 3442-3445. For a representative example with
$\mathrm{Au}(\mathrm{I})$ involving neighboring group participation, see: (d) Wang, W.; Xu, B.; Hammond, G. B. J. Org. Chem. 2009, 74, 1640-1643.

(27) We note that in the metal-free control experiments in Table 5, alkenyl chloride product formation was observed at $150{ }^{\circ} \mathrm{C}$ (albeit in low yields). A variant of Pathway B2 in which palladium(II) is replaced with $\mathrm{H}^{+}$may account for the apparent regiochemical preference for $\mathbf{2 2} \mathbf{b}$ over $\mathbf{2 2} \mathbf{b}^{\prime}$ in the absence of palladium(II). In the case of $22 \mathbf{a}$, the conversion was too low in the absence of metal to accurately measure the regiochemical ratio.

(28) (a) Bacchi, A.; Costa, M.; Della Cá, N.; Gabriele, B.; Salerno, G.; Cassoni, S. J. Org. Chem. 2005, 70, 4971-4979. (b) Beccalli, E. M.; Borsini, E.; Broggini, G.; Palmisano, G.; Sottocornola, S. J. Org. Chem. 2008, 73, 4746-4749.

(29) Compound 31 was prepared via a palladium(II)-catalyzed cycloisomerization of $21 \mathrm{a}$, which takes place in the absence of $\mathrm{Cl}^{-}$ under slightly modified reaction conditions. For more details, see the Supporting Information.

(30) Jin, C.; Burgess, J. P.; Kepler, J. A.; Cook, C. E. Org. Lett. 2007, 9, 1887-1890.

(31) (a) Blackmond, D. G. Angew. Chem. Int. Ed. 2005, 44, 43024320; (b) Mathew, J. S.; Klussmann, M.; Iwamura, H.; Valera, F.; Futran, A.; Emanuelsson, E. A. C.; Blackmond, D. G. J. Org. Chem. 2006, 71, 4711-4722; (c) Blackmond, D. G. J. Am. Chem. Soc. 2015, 137, 10852-10866. 


$$
\begin{gathered}
\text { • Pdll loadings as low as } 25 \mathrm{ppm} \\
\text { • high regio- and stereoselectivity } \\
\text { - removable directing groups (DGs) }
\end{gathered}
$$

